\title{
Concentrations of Thiocyanate and Hypothiocyanite in the Saliva of Young Adults
}

\author{
Rosnah Abdul Jalil \\ (Received 9 August 1993 and accepted 31 Augusut 1994)
}

Key words: saliva, thiocyanate, hypothiocyanite

\begin{abstract}
The study was conducted to determine thiocyanate $\left(\mathrm{SCN}^{-}\right)$and hypothiocyanite $\left(\mathrm{OSCN}^{-}\right)$concentrations in resting (RWS) and stimulated whole saliva (SWS) and stimulated parotid saliva (SPS) of 20 healthy young adults aged 21-29 y. Samples of saliva were collected at 12:30, immediately before lunch. Resting saliva was collected by expectoration, and stimulated saliva was collected during the uniform chewing of paraffin wax. Parotid secretion was collected using a modified Carlsson-Crittenden cup (Carlsson et al., Am, J. Physiol., 26, 169-177, 1910). SCN ${ }^{-}$concentration was determined by the ferric nitrate method (Betts et al., J. Am. Chem. Soc., 75, 5721-5727, 1953) whilst OSCN $^{-}$was assayed using 2-mercaptoethanol as a reducing agent(Pruitt et al., Caries Res., 16, 315-323, 1982). In RWS, SWS and SPS, the mean SCN ${ }^{-}$concentrations (in $\mathrm{mM}$ ) were $1.48 \pm 0.59$ (S.D.), $0.90 \pm 0.56$ (S.D.) and $1.24 \pm 0.65$ (S.D.) whilst the mean $\mathrm{OSCN}^{-}$concentrations (in $\mu \mathrm{M}$ ) were $31.21 \pm 13.54$ (S.D.), $24.90 \pm 12.61$ and $30.19 \pm 23.35$ (S.D.) in the respective salivas. The presence of $\mathrm{OSCN}^{-}$in the secretion collected from the parotid gland supported previous findings by Tenovuo and Pruitt (Tenovuo et al., J. Oral Path, ol. 13, 573-584, 1984), who suggested an endogenous glandular (eukaryotic) source of hydrogen peroxide $\left(\mathrm{H}_{2} \mathrm{O}_{2}\right)$, since parotid saliva from healthy glands is devoid of bacteria and leukocytes.
\end{abstract}

\section{Introduction}

The salivary peroxidase system consists of salivary peroxidase enzyme, $\mathrm{H}_{2} \mathrm{O}_{2}$ and $\mathrm{SCN}^{-}$. This system may contribute to the antimicrobial properties of saliva, as shown in numerous in vitro studies ${ }^{[1-3]}$. The source of $\mathrm{H}_{2} \mathrm{O}_{2}$ in the oral environment may be leukocytes, oral bacteria and other host cells.

$\mathrm{SCN}^{-}$concentration is related to dietary habits and smoking. The salivary glands concentrate $\mathrm{SCN}^{-}$ from blood through the epithelial cells of the striated duct and subsequently secrete $\mathrm{SCN}^{-}$at relatively high concentrations ${ }^{[4]}$.

Salivary peroxidase enzyme catalyzes the oxidation of $\mathrm{SCN}^{-}$by $\mathrm{H}_{2} \mathrm{O}_{2}$ to yield the antimicrobial oxidizing agent, $\mathrm{OSCN}^{-}$:

$\mathrm{H}_{2} \mathrm{O}_{2}+\mathrm{SCN}^{-} \rightarrow \mathrm{H}_{2} \mathrm{O}+\mathrm{OSCN}^{-}$.

$\mathrm{OSCN}^{-}$is the major product at neutral $\mathrm{pH}$, whereas at low $\mathrm{pH}$, the major product is hypothiocyanous acid (HOSCN), which is in acid-base equilibrium with $\mathrm{OSCN}^{-}$:

$\mathrm{H}^{+}+\mathrm{OSCN}^{-} \rightarrow \mathrm{HOSCN}$.

The antibacterial action is more effective at low $\mathrm{pH}$, owing to the ability of uncharged HOSCN to penetrate microbial cell membranes more readily than $\mathrm{OSCN}^{-}$, and thus attack groups of essential intracellular enzymes. However this neutral acid, HOSCN, decomposes rapidly ${ }^{[5]}$.

The concentration of $\mathrm{OSCN}^{-}$found in saliva depends upon the method of collection. Upon stimulation, the $\mathrm{OSCN}^{-}$concentration decreases and remains low throughout the period of stimulation.

$\mathrm{OSCN}^{-}$has also been identified in parotid saliva, and since parotid saliva from healthy glands is devoid of bacteria and leucocytes, this suggests an endogenous glandular (eukaryotic) source of $\mathrm{H}_{2} \mathrm{O}_{2}{ }^{[6]}$.

Department of Oral Pathology, Oral Medicine and Periodontology, Faculty of Dentistry

To whom all correspondence should be addressed: Dr. R. A. Jalil, Department of Oral Pathology, Oral Medicine and Periodontology, Faculty of Dentistry, University of Malaya, 59100 Kuala Lumpur, MALAYSIA. 
The objectives of this study were to compare the assay methods which have been used to measure $\mathrm{OSCN}^{-}$in saliva in view of the wide range of reported results, and to investigate the effect of stimulation on the concentrations of $\mathrm{SCN}^{-}$and $\mathrm{OSCN}^{-}$in whole saliva as well as to determine the levels of $\mathrm{SCN}^{-}$and $\mathrm{OSCN}^{-}$in stimulated parotid saliva(SPS).

\section{Saliva collection}

\section{Materials and Methods}

The subjects were 20 healthy dental students and dental personnel aged 21-29 y with a mean age of 24 y (S.D.=1.92). Samples of saliva were collected using a modified Carlsson-Crittinden ${ }^{[7]}$ cup immediately before lunch at 12:30. For resting whole saliva(RWS), the subjects were instructed to refrain from all tongue and jaw movements except when transferring saliva every $30 \mathrm{~s}$ into an ice-chilled graduated tube.

Stimulated whole saliva(SWS) was achieved by paraffin wax chewing (Orion Diagnostica, Finland) at a constant rate of one chew per second, and the saliva was then transferred into a tube every $15 \mathrm{~s}$. Subjects switched chewing from one side of the mouth to the other every $15 \mathrm{~s}$.

Parotid secretion was collected from one gland in each subject via a modified Carlsson-Crittenden cup placed over the orifice of Stensen's duct, and carried by polyethylene tubing (tubing TSR, Slaughter Ltd., Essex, U.K.) to a graduated tube standing in ice. Stimulation was provided by chewing paraffin wax on the side of the mouth where the collecting device was placed.

For the three types of saliva, the time taken to collect approximately $2.4 \mathrm{ml}$ was noted.

\section{Analysis of $\mathrm{SCN}^{-}$and $\mathrm{OSCN}^{-}$}

Aliquots of $200 \mu 1$ of saliva were utilized for estimation of $\mathrm{OSCN}^{-}$, which was analyzed immediately in duplicate. In addition, an 800- $\mu 1$ sample of saliva was immediately centrifuged at 13,000 rpm for $20 \mathrm{~min}$ at $4{ }^{\circ} \mathrm{C}$ and the supernatant stored at $-17^{\circ} \mathrm{C}$ for later analysis of $\mathrm{SCN}^{-}$.

$\mathrm{SCN}^{-}$concentration was determined by the ferric nitrate method ${ }^{[8]}$, whilst ${ }^{[9]} \mathrm{OSCN}^{-}$was assayed using 2-mercaptoethanol as a reducing agent, working at a $\mathrm{pH}$ of 8 . The absorbances for $\mathrm{SCN}^{-}$and $\mathrm{OSCN}^{-}$ analyses were read using a spectrophotometer(Unicam SP1700, Ultraviolet, Cambridge, U.K.).

Detection of $\mathrm{OSCN}^{-}$in saliva using 5-thio-2-nitrobenzoic acid (TNB) was first described by Thomas et al. ${ }^{[10]}$ and the method was subsequently modified by Pruitt et al ${ }^{[9]}$ These two procedures were compared prior to the start of the study using samples of SWS collected from 10 volunteers working in the laboratory. TNB was first prepared by reduction of 5,5'-dithiobis (2-nitrobenzoic acid)(DTNB) with agents such as borohydride ${ }^{[10]}$ or 2-mercaptoethanol ${ }^{[9]}$. The assay of $\mathrm{OSCN}^{-}$is based on oxidation of 2 mol of TNB to colorless DTNB by $1 \mathrm{~mol}$ of $\mathrm{OSCN}^{-}$.

\section{Data analysis}

The SPSSX was used to determine mean values, standard deviations and frequency distributions. In order to explore relationships between the salivary components, Pearson's correlation coefficients were calculated between the two sets of measurements.

\section{Reproducibility}

Reproducibility of $\mathrm{SCN}^{-}$and $\mathrm{OSCN}^{-}$measurements was also determined prior to the start of the study. For this, samples of stimulated saliva were collected from eight volunteers working in the laboratory. Pearson's correlation coefficients between the two measurements were calculated, and values of 0.99 and 0.96 were attained for $\mathrm{SCN}^{-}$and $\mathrm{OSCN}^{-}$estimations, respectively. There were no statistically significant differences between the means (data not shown).

\section{Results}

Table 1 shows that the two procedures used for assay of hypothiocyanite gave essentially the same results. There were no statistically significant differences between the values obtained. 
Table 1 Comparison of two different techniques for assay of $\mathrm{OSCN}^{-}$

\begin{tabular}{ccc}
\hline Subject number & Method of Pruitt et al. ${ }^{[10]}$ & Method of Thomas et al. ${ }^{[9]}$ \\
\hline 1 & 12.24 & 5.25 \\
2 & 58.56 & 67.94 \\
3 & 27.46 & 26.33 \\
4 & 19.85 & 22.39 \\
5 & 26.80 & 30.19 \\
6 & 15.55 & 32.27 \\
7 & 10.81 & 15.83 \\
8 & 18.75 & 24.78 \\
9 & 21.29 & 27.72 \\
10 & 26.03 & 23.39 \\
& & \\
Mean & 23.73 & 27.61 \\
S.D. & 13.55 & 16.15 \\
\hline Wilcoxon's signed rank test & & \\
\hline
\end{tabular}

Although samples of saliva were collected from all of the 20 subjects participating in the study, the data were incomplete for thiocyanate due to analytical loss. Table 2 presents the mean flow rates and concentrations of $\mathrm{SCN}^{-}$and $\mathrm{OSCN}^{-}$in RWS, SWS and SPS of the participating subjects. In whole saliva the onset of stimulation was marked by a substantial increase in mean flow rate. The flow rate of SPS was comparable to that of RWS.

Table 2 Flow rate (FR) and concentrations of thiocyanate $\left(\mathrm{SCN}^{-}\right)$and hypothiocyanite $\left(\mathrm{OSCN}^{-}\right)$in RWS, SWS and SPS with standard deviations in parenthesis.

\begin{tabular}{lccc}
$\begin{array}{r}\mathrm{n}=20 \\
{ }^{*} \mathrm{n}=19\end{array}$ & \multicolumn{2}{l}{} \\
\hline \multirow{2}{*}{$\mathrm{RWS}$} & $\begin{array}{c}\mathrm{FR} \\
(\mathrm{ml} / \mathrm{min})\end{array}$ & $\begin{array}{c}\mathrm{SCN}^{-} \\
(\mathrm{mM})\end{array}$ & $\begin{array}{c}\mathrm{OSCN}^{-} \\
(\mu \mathrm{M})\end{array}$ \\
& 0.46 & $* 1.48$ & 31.21 \\
SWS & $(0.24)$ & $(0.59)$ & $(13.54)$ \\
& 1.62 & $* 0.90$ & 24.90 \\
SPS & $(0.86)$ & $(0.56)$ & $(12.61)$ \\
& 0.43 & 1.24 & 30.19 \\
& $(0.33)$ & $(0.65)$ & $(23.35)$ \\
\hline
\end{tabular}

$\mathrm{n}=20$

${ }^{*} n=19$

Stimulation resulted in a decrease in the mean concentrations of both $\mathrm{SCN}^{-}$and $\mathrm{OSCN}^{-}$in whole saliva. The concentrations of $\mathrm{SCN}^{-}$and $\mathrm{OSCN}^{-}$in SPS were comparable to those in RWS.

Figs. 1, 2 and 3 show the correlation coefficients between $\mathrm{SCN}^{-}$and $\mathrm{OSCN}^{-}$in RWS, SWS and SPS. There were no statistically significant correlations between $\mathrm{SCN}^{-}$and $\mathrm{OSCN}^{-}$concentrations in $\mathrm{RWS}(\mathrm{r}=$ $0.26, \mathrm{p}>0.05$ ). However, the relationship between the concentration of $\mathrm{SCN}^{-}$and $\mathrm{OSCN}^{-}$in SWS was significant $(r=0.60, p<0.05)$, the levels in SPS approaching the levels of statistical significance $(r=0.54, p=0.08)$. 
Hypothiocyanite $(\mu \mathrm{M})$

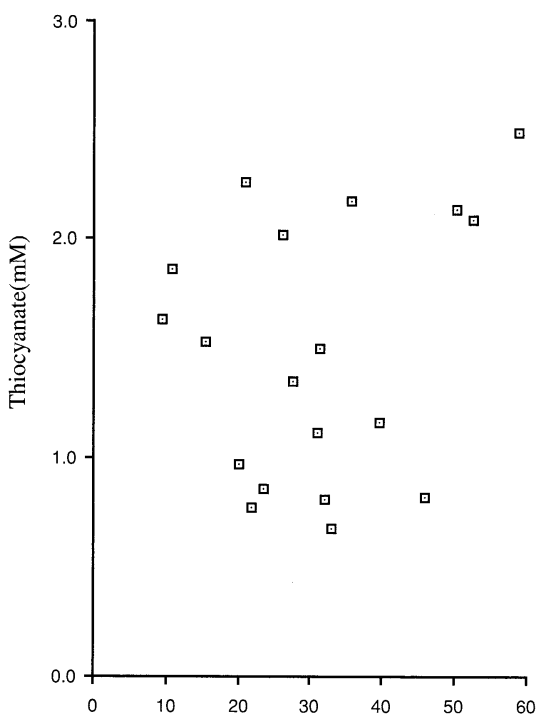

Fig. 1

Correlation between thiocyanate $\left(\mathrm{SCN}^{-}\right)$and hypothiocyanite $\left(\mathrm{OSCN}^{-}\right)$concentrations in RWS $\mathrm{n}=19$
Hypothiocyanite $(\mu \mathrm{M})$

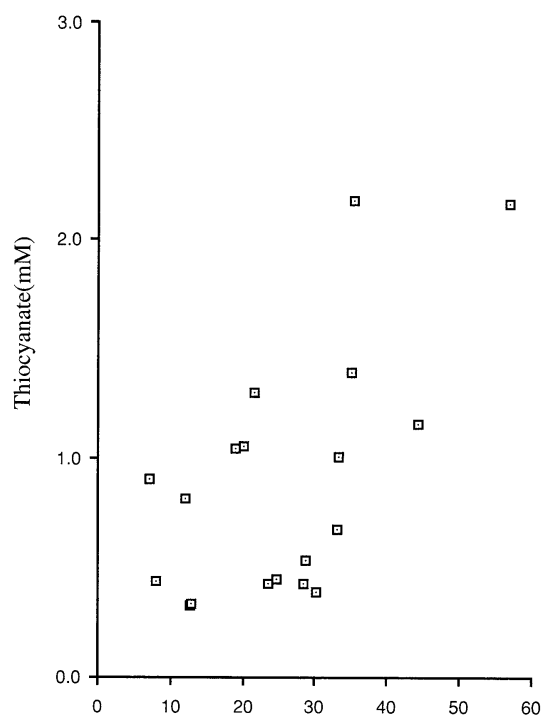

Fig. 2

Correlations between thiocyanate $\left(\mathrm{SCN}^{-}\right)$and hypothiocyanite $\left(\mathrm{OSCN}^{-}\right)$concentrations in SWS $\mathrm{n}=19$

Hypothiocyanite $(\mu \mathrm{M})$

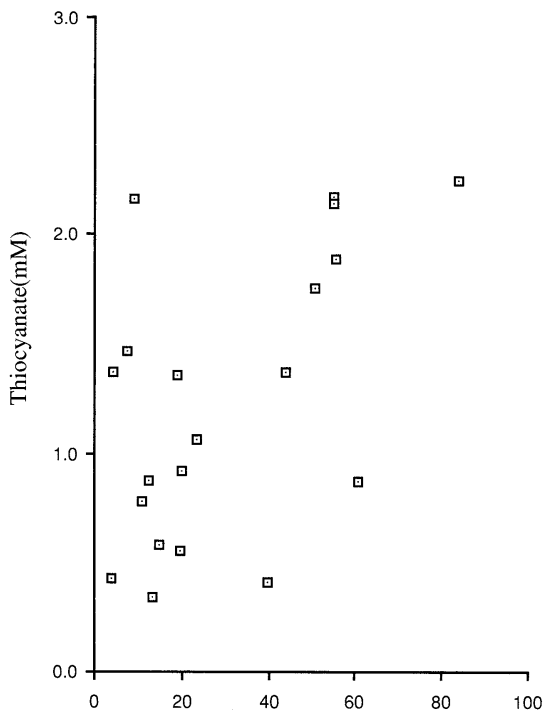

Fig. 3

Correlations between thiocyanate $\left(\mathrm{SCN}^{-}\right)$and hypothiocyanite $\left(\mathrm{OSCN}^{-}\right)$concentrations in SPS $\mathrm{n}=20$ 


\section{Discussion}

Comparison of the methods which have been used to measure $\mathrm{OSCN}^{-}$in saliva indicated that they gave similar results. Slightly lower values were obtained when the assay was performed using the method of Pruitt et al. ${ }^{[5]}$ These differences were not sufficient to account for the wide range of $\mathrm{OSCN}^{-}$values reported.

Earlier studies of $\mathrm{SCN}^{-}$concentration in RWS, SWS and SPS are presented in Table 3. In this study, the $\mathrm{SCN}^{-}$concentration in whole saliva was reduced on stimulation, consistent with a previous study conducted in adolescents ${ }^{[11]}$. The levels of $\mathrm{SCN}^{-}$in adults in this study are comparable to those reported by Pruitt et al. ${ }^{[5]}$ and Lamberts et al..$^{[12]}$ The values in adolescents ${ }^{[1]}$ are lower than those in adults, and this may reflect age differences as well as smoking experience. Maliszewski et al. ${ }^{[13]}$ reported that $\mathrm{SCN}^{-}$concentrations are higher in the saliva of smokers than in that of non-smokers. Lamberts et al. ${ }^{[12]}$ carried out thiocyanate estimations in two groups of subjects, smokers and non-smokers, and reported that $\mathrm{SCN}^{-}$levels in RWS were higher in the former than in the latter. Tenovuo et al. ${ }^{[14]}$ reported an even lower mean $\mathrm{SCN}^{-}$level of $0.38 \mathrm{mM}$ in RWS of children aged between 0.8 and $3.8 \mathrm{y}$.

Table 3 Thiocyanate $\left(\mathrm{SCN}^{-}\right)$concentrations $(\mathrm{mM})$ in RWS, SWS and SPS in the present and other studies

\begin{tabular}{|c|c|c|c|}
\hline Authors & $\mathrm{n}$ & age & mean \pm S.D. \\
\hline \multicolumn{4}{|l|}{ RWS } \\
\hline Present study & 19 & $21-29$ & $1.48 \pm 0.59$ \\
\hline $\mathrm{Jalil}^{[11]}$ & 92 & $12-14$ & $0.71 \pm 0.42$ \\
\hline Lamberts et al. ${ }^{[12]}$ & 29 & $17-29$ & $1.46 \pm 0.86$ \\
\hline Pruitt et al. ${ }^{[5]}$ & 28 & $20-50$ & $1.21 \pm 0.66$ \\
\hline Tenovuo et al. ${ }^{[14]}$ & 16 & $0.8-3.8$ & $0.38 \pm 0.18$ \\
\hline \multicolumn{4}{|l|}{ SWS } \\
\hline Present study & 19 & $21-29$ & $0.90 \pm 0.56$ \\
\hline $\mathrm{Jalil}^{[11]}$ & 93 & $12-14$ & $0.34 \pm 0.20$ \\
\hline Grahn et al. ${ }^{[15]}$ & 50 & $19-21$ & $1.71 \pm 0.57$ \\
\hline Tenovuo et al. ${ }^{[14]}$ & 35 & $17-61$ & $1.57 \pm 0.75$ \\
\hline Tenovuo \& Anttonen ${ }^{[16]}$ & 13 & $22-37$ & $1.12 \pm 0.55$ \\
\hline \multicolumn{4}{|l|}{ SPS } \\
\hline Present study & 20 & $21-29$ & $1.24 \pm 0.65$ \\
\hline Pruitt et al. ${ }^{[5]}$ & 28 & $20-50$ & $0.76 \pm 0.55$ \\
\hline
\end{tabular}

In SWS, the values obtained from the present adult population are lower than those reported by Grahn et al. ${ }^{[15]}$ and Tenovuo et al..$^{[16,17]}$. However, half the subjects in these studies were smokers, in contrast to our subjects, few of whom smoked.

The $\mathrm{SCN}^{-}$levels in SPS were higher than those reported by Pruitt et al ${ }^{[5]}$. No data have previously been presented on $\mathrm{SCN}^{-}$levels in the parotid secretions of adolescents. The present study appears to indicate that $\mathrm{SCN}^{-}$levels in both RWS and SWS in adolescents are lower than those in adults.

The $\mathrm{OSCN}^{-}$concentration in whole saliva dropped upon stimulation of the saliva flow rate. According to Globerman et al. ${ }^{[18]}$ the oxygen concentration in whole saliva decreases sharply upon stimulation, and this could result in decreased $\mathrm{H}_{2} \mathrm{O}_{2}$ production in saliva with a subsequent decrease of the $\mathrm{OSCN}^{-}$level. Tenovuo et al. ${ }^{[17]}$ suggested that $\mathrm{OSCN}^{-}$might be eliminated by reducing agents released into 
saliva upon stimulation, and that the source of reducing agents could be salivary secretions, oral tissues or oral bacteria. Evidence for such reducing agents was provided by the 'negative' $\mathrm{OSCN}^{-}$values reported, which indicated that DTNB was reduced to TNB. Although previous work carried out in our laboratory to estimate $\mathrm{OSCN}^{-}$in SWS has yielded some negative $\mathrm{OSCN}^{-}$values, no negative $\mathrm{OSCN}^{-}$values were found in the saliva of the present subjects. In this study there was some evidence of an association between the concentrations of $\mathrm{SCN}^{-}$and $\mathrm{OSCN}^{-}$, as seen in SWS. Hence, it may be assumed that one of the factors that may account for the decrease in the concentration of $\mathrm{OSCN}^{-}$upon stimulation might be a reduction in the amount of $\mathrm{SCN}^{-}$present.

As seen in Table 4, $\mathrm{OSCN}^{-}$levels in RWS have varied considerably in different investigations. This variation was probably due to differences in the assay methods, pretreatment procedures or sample collection techniques. The values of $\mathrm{OSCN}^{-}$in adolescents were slightly lower than in the adult population.

Table 4 Hypothiocyanite $\left(\mathrm{OSCN}^{-}\right)$concentrations ( $\left.\mu \mathrm{M}\right)$ in RWS, SWS and SPS in the present and other studies.

\begin{tabular}{llll}
\hline Authors & $\mathrm{n}$ & age & mean \pm S.D. \\
\hline RWS & & & \\
& 20 & $21-29$ & $31.21 \pm 13.54$ \\
Present study & 89 & $12-14$ & $20.79 \pm 10.58$ \\
${\text { Jalili }{ }^{[11]}}^{\text {Mandel et al. }{ }^{[19]}}$ & 10 & $24-40$ & $17.60 \pm 17.70$ \\
Lamberts et al. $^{[12]}$ & 29 & $17-29$ & $47.10 \pm 26.00$ \\
\hline SWS & & & \\
& 20 & $21-29$ & $24.90 \pm 12.61$ \\
Present study & 30 & $17-39$ & \\
Tenovuo et al. ${ }^{[14]}$ & & & \\
\hline SPS & & $21-29$ & $15.00 \pm 12.00$ \\
\hline Present study & 20 & $24-40$ & 8.70 \\
Mandel et al. ${ }^{[19]}$ & 10 & & \\
\hline
\end{tabular}

The $\mathrm{OSCN}^{-}$concentration in stimulated whole saliva in this investigation was lower than that in resting whole saliva. Similar findings have been reported by other workers ${ }^{[6,13]}$.

The $\mathrm{OSCN}^{-}$concentration in stimulated parotid saliva from the present adult population was comparable to levels in RWS. This finding differs from that reported by Mandel et al. ${ }^{[19]}$, where $\mathrm{OSCN}^{-}$levels in SPS were found to be lower than in RWS. This may have been due to differences in the stimulation technique employed. The presence of $\mathrm{OSCN}^{-}$in the secretion collected from the parotid gland suggests an endogenous glandular source of $\mathrm{H}_{2} \mathrm{O}_{2}$, since parotid saliva from healthy glands is devoid of bacteria and leukocytes ${ }^{[5]}$.

\section{Conclusions}

Comparison of the methods which have been used to measure $\mathrm{OSCN}^{-}$in saliva indicates that these methods gave similar results.

Stimulation of the saliva flow results in a rapid decrease in $\mathrm{OSCN}^{-}$levels in whole saliva. This effect may be due in part to decreased concentrations of $\mathrm{SCN}^{-}$, as well as to elimination of $\mathrm{OSCN}^{-}$by reducing agents released into the stimulated saliva.

The antimicrobial activity of the salivary peroxidase system may be more effective during periods in 
which saliva flow is unstimulated (such as during sleep).

The presence of $\mathrm{OSCN}^{-}$in parotid secretions suggests an endogenous source of $\mathrm{H}_{2} \mathrm{O}_{2}$.

\section{Reference}

[ 1 ] Bjorck, L., Rosen, C.G., Marshall, V. and Reiter, B.: Antibacterial activity of the lactoperoxidase system in milk against Pseudomonas and other gram-negative bacteria, Appl. Microbiol., 30, 199-204, 1975

[2] Tenovuo, J. and Knuuttila, M.L.E.: Antibacterial effect of salivary peroxidase on a cariogenic strain of Streptococcus mutans, J. Dent. Res., 56, 1608-1613, 1977

[ 3 ] Thomas, E.L., Pera, K.A., Smith, K.W. and Chwang, A.K.: Inhibition of Streptococcus mutans by the lactoperoxidase antimicrobial system, Infect. Immun., 39, 767-768, 1983

[ 4 ] Wood, J.L.: Biochemistry. In Chemistry and biochemistry of thiocyanic acid and its derivatives, 156221, Newman, A.A., ed., Academic press, 156-221, 1975

[ 5 ] Pruitt, K.M., Mansson-Rahemtulla, B. and Tenovuo, J.: Detection of the hypothiocyanite (OSCN $\left.{ }^{-}\right)$ ion in human parotid saliva and the effect of $\mathrm{pH}$ on $\mathrm{OSCN}^{-}$generation in the salivary peroxidase antimicrobial system, Arch. Oral Biol., 28, 517-525, 1983

[6] Tenovuo, J. and Pruitt, K.M.: Relationship of the human salivary peroxidase system to oral health, $J$. Oral Pathol., 13, 573-584, 1984

[ 7 ] Carlsson, A.V. and Crittenden, A.L.: The relation of ptyalin concentration to the diet and to the rate of secretion of the saliva, Am. J. Physiol., 26, 169-177, 1910

[ 8 ] Betts, R.H. and Dainton, F.S.: Electron transfer and other processes involved in the spontaneous bleaching of acidified solutions of ferric thiocyanate, J. Am. Chem. Soc., 75, 5721-5727, 1953

[9] Pruitt, K.M., Tenovuo, J., Fleming, W. and Adamson, M.: Limiting factors for the generation of hypothiocyanite ion, an antimicrobial agent in human saliva, Caries Res., 16, 315-323, 1982

[10] Thomas, E.L., Bates, K.P. and Jefferson, M.M.: Hypothiocyanite ion: Detection of the antimicrobial agent in human saliva, J. Dent. Res., 59, 1466-1472, 1980

[11] Jalil, R.A.: Salivary concentrations of thiocyanate, hypothiocyanite, lysozyme, lactoferrin and secretory immunoglobulin A related to plaue, gingivitis and caries in children and young adults (dissertation), University of London, 1989

[12] Lamberts, B.I., Pruitt, E.D., Pederson, E.D. and Golding, M.P.: Comparison of salivary peroxidase system components in caries-free and caries-active naval recruits, Caries Res., 18, 488-494, 1984

[13] Maliszewski, T.F. and Bass, D.E.: True and apparent thiocyanate in body fluids of smokers and nonsmokers, J. Appl. Physiol., 8, 289-296, 1955

[14] Tenovuo, J., Lehtonen, O-P., Aaltonen, A., Vilja, P. and Tuohimaa, P.: Antimicrobial factors in whole saliva of human infants, Infect. Immun., 51, 49-53, 1986

[15] Grahn, E., Tenovuo, J., Lehtonen, O-P., Eerola, E. and Vilja, P.: Antimicrobial systems of human whole saliva in relation to dental caries, cariogenic bacteria and gingival inflammation in young adults, Acta Odont. Scand., 46, 67-74, 1988

[16] Tenovuo, J. and Anttonen, T.: Peroxidase-catalysed hypothiocyanite production in human salivary sediment in relation to oral health, Caries Res., 14, 269-275, 1980

[17] Tenovuo, J., Moldoveanu, Z., Mestecky, J., Pruitt, K. and Rahemtulla, B.: Interaction of specific and innate factors of immunity: $\operatorname{IgA}$ enhances the antimicrobial effect of the lactoperoxidase system against Streptococcus mutans, J. Immunol., 128, 726-731, 1982

[18] Globerman, D.Y. and Kleinberg, I.: Intra-oral $\mathrm{pO}_{2}$ and its relation to bacterial accumulation on the oral tissues. In Saliva and Dental Caries, a special supplement to Microbiology Abstracs, 275-292, Kleinberg, I. et al., eds., Information Retrieval, New York, 1979

[19] Mandel, I.D., Behrman, J., Levy, R. and Weinstein, D.: The salivary lactoperoxidase system in cariesresistant and caries-susceptible adults, J. Dent. Res. 62, 922-925, 1983 